\title{
POLÍTICAS DE ACESSO AO ENSINO SUPERIOR PARA ESTUDANTES COM DEFICIÊNCIA NO CHILE E NO BRASIL
}

\author{
POLÍTICAS DE ACCESO A LA EDUCACIÓN SUPERIOR PARA ESTUDIANTES CON \\ DISCAPACIDAD EN CHILE Y BRASIL
}

\author{
POLICIES FOR ACCESS TO HIGHER EDUCATION FOR STUDENTS WITH \\ DISABILITIES IN CHILE AND BRAZIL
}

Noemi Nascimento ANSAY ${ }^{1}$

Laura Ceretta MOREIRA ${ }^{2}$

\begin{abstract}
RESUMO: O objetivo deste artigo é discutir as políticas de acesso para estudantes com deficiência, e sua implementação na Universidade de Talca (UTALCA), no Chile, e na Universidade Federal do Paraná (UFPR), no Brasil, no período de 1990 a 2016. A pesquisa foi realizada a partir da metodologia da educação comparada, identificando diferenças e semelhanças, discutindo a atualidade (à época da pesquisa) e as perspectivas futuras para esses grupos de estudantes no ensino superior de ambos os países. Para construção dos dados, além da pesquisa bibliográfica e documental, foram realizadas entrevistas semiestruturadas com 33 estudantes com deficiência e quatro gestores das duas universidades. Constatou-se, após a análise do contexto educacional, das políticas de financiamento e das políticas de acesso ao ensino superior no Chile e no Brasil que, apesar do aparato legal que garante os direitos educacionais das pessoas com deficiência, a maioria delas está excluída deste nível de ensino.
\end{abstract}

PALAVRAS-CHAVE: Estudantes com deficiência. Ensino superior. Políticas de acesso ao ensino superior.

RESUMEN: El objetivo de este artículo es el de las políticas de acceso para estudiantes con discapacidades y su implementación en la Universidad de Talca (UTALCA), en Chile, y en la Universidad Federal de Paraná (UFPR), en Brasil, en el período de 1990 a 2016. La investigación comparada, la identificación de las diferencias y las semánticas, se refierem a la realidad (en el momento de la investigación) y las perspectivas futuras para los grupos de estudiantes que no son superiores a los de otros países. Para la construcción de los datos, la investigación bibliográfica y documental, se realizaron entrevistas semiestruturadas con 33 estudiantes con discapacidades y quatro gestores de las universidades. Constatou-se, após a analise do contexto educacional, las políticas de financiamiento y las políticas de acceso a la escuela superior en Chile y Brasil, el sistema legal y garante de la educación de las personas

\footnotetext{
1 Universidade Estadual do Paraná (UNESPAR), Paranavaí - PR - Brasil. Professora adjunta, nível B, Mediadora do Programa de Enriquecimento Instrumental (PEI). Coordenadora do NESPI (Núcleo de Educação Especial/Inclusiva) do Campus II Curitiba (UNESPAR). ORCID: https://orcid.org/0000-0001-6881-966X. Email: noemiansay@gmail.com

${ }^{2}$ Universidade Federal do Paraná (UFPR), Curitiba - PR - Brasil. Professora associada IV da UFPR no setor de Educação no departamento de planejamento e administração escolar e no programa de pós-graduação em Educação. ORCID: https://orcid.org/0000-0003-4569-7369. E-mail: laurac.moreira@gmail.com
} 
con deficiencias, todos los casos y servicios, y dos avanços no ingresso, a maioria delas está excluída deste nível de ensino.

PALABRAS CLAVE: Estudiantes con discapacidad. Educación superior. Políticas de acceso a la educación superior.

ABSTRACT:The general objective of this research is to investigate access policies for students with disabilities and their implementation at the University of Talca (UTALCA), in Chile, and at the Federal University of Paraná (UFPR), in Brazil. The survey was conducted in the light of comparative studies, identifying differences and similarities, discussing the present (when the research was done) and the future prospects for this group of students, attending higher education in both countries. Therefore, for data construction, beyond the literature and documentary research, there were conducted semi-structured interviews with 33 students with disabilities and four coordinators of the two universities. It was found after analyzing the educational policy, in the context of funding and access policies for higher education in Chile and Brazil, that despite the legal apparatus that ensures the educational rights of people with disabilities at all levels and modalities, and the advances concerning to admission, most of them are excluded from this level of education.

KEYWORDS: Students with disabilities. Higher education in Chile. Higher education in Brazil. Policies for access to higher education.

\section{Introdução}

Chile e Brasil são países latino-americanos com trajetórias históricas, educacionais e políticas singulares. Ambos, no entanto, têm o desafio de garantir o acesso de pessoas com deficiência no ensino superior. As políticas denominadas "inclusivas", nacionais e internacionais, advertem para o direito desses sujeitos alcançarem todos os níveis de ensino, de forma a garantir sua formação pessoal e profissional, assim como impõem ações institucionais às universidades.

Em ambos os países, a educação constitui-se um direito de todas as pessoas. A Constituição do Chile (CHILE, 2010) afirma em seu artigo no 10: "A Educação tem por objeto o pleno desenvolvimento da pessoa nas distintas etapas da sua vida". Também a Constituição brasileira (BRASIL,1988) proclama: “A educação, direito de todos e dever do Estado e da família, será promovida e incentivada com a colaboração da sociedade [...].” (Art. 205).

Além disso, políticas voltadas para estudantes com deficiência, nos dois países, garantem sua transversalidade em todos os níveis e modalidades de ensino. No Chile, a Lei Geral da Educação (BOLETín No 4970-04) e, no Brasil, a Lei de Diretrizes e Bases da Educação (LDB, 1996). 
No Chile, houve uma expansão do ensino universitário. De acordo com o Serviço de Informação da Educação Superior (SIES), em 1983 o total de matrículas foi de 172.995 estudantes e, em 2011, de 1.015.150 (CHILE, s/p.). Estes dados mostram um aumento de 586,9\% no período, de acordo com o Ministério da Educação (MINEDUC, 2012). Quanto ao número de estudantes com deficiência que ingressaram no ensino superior, de acordo com o Serviço Nacional de pessoas com deficiência (SENADIS, 2012 s/p): “[...] só um a cada quinze estudantes com deficiência consegue ingressar na Educação Superior.”

No Brasil foi realizada uma análise dos dados dos censos de 2003 e de 2013, do Ministério da Educação e do Instituto Nacional de Estudos e Pesquisas Educacionais Anísio Teixeira (MEC/INEP), sobre os estudantes matriculados na graduação no país. Encontrou-se uma evolução importante nos números de matrículas de estudantes com deficiência no ensino superior. Este grupo passou de 5.078, para 23.250, respectivamente. Isso significou um aumento na participação, que foi de $0,13 \%$ em 2003 para 0,34\%, em 2011. Neste mesmo período, houve um aumento de $73,4 \%$ no total de estudantes matriculados, que passaram de 3.887.022 para 6.739.689. (MEC/INEP, 2013).

Apesar do crescimento significativo observado nos dados estatísticos quanto ao ingresso desse alunado no ensino superior no Chile e no Brasil, este número é insuficiente diante do percentual das pessoas excluídas desse nível do processo educacional. Desta maneira, a problemática a ser discutida nesse texto formula-se da seguinte maneira: Em que contexto as políticas de acesso ao ensino superior foram formuladas e implementadas no Chile e no Brasil a partir de 1990? Em que medida essas políticas garantem o acesso de estudantes com deficiência ao ensino superior na Universidade de Talca (Chile) e na Universidade Federal do Paraná (UFPR)?

Na pesquisa foi utilizada a metodologia dos estudos comparados, de acordo com as fases descritas por Ferrer (2002): pré-descritiva, descritiva, interpretativa, de justaposição e de comparação. Para construção dos dados, além da pesquisa bibliográfica e documental, foram realizadas entrevistas semiestruturadas com 33 estudantes com deficiência e quatro gestores das duas universidades. Na análise do conteúdo das respostas das entrevistas foram utilizados, como principal referência, os estudos de Bardin (1979). 


\section{Contexto Educacional do Chile}

O Chile é um país democrático, unitário, em que a administração funcional e a territorial são descentralizadas, de acordo com a Constituição Política da República do Chile (1980). Quanto aos dados demográficos, a população do Chile é formada por 16.634.603 habitantes (SENADIS, 2012).

O sistema econômico chileno se caracteriza pela liberalização da economia. Desde os anos de 1970, “as autoridades assumiram sem contrapeso 'o mercado' como política econômica do país, incluindo todos os setores (exceto a defesa).” (DÍAZ, 2005, p. 53). Ideologicamente, a economia do país baseia-se na perspectiva do "antiestado", de cunho neoliberal, onde o papel do Estado é favorecer a atuação do mercado (DÍAZ, 2005). O impacto dessa política caracteriza-se por forte desigualdade social e pouca participação social nas decisões dos rumos do país. Não é despretensiosa a afirmação do Banco Mundial (2014) de que o Chile é uma das economias que mais cresceu na última década, na América Latina, e que suas "políticas criativas" se converteram em modelos internacionais de um bom governo (BANCO MUNDIAL, 2014). Desta maneira, as políticas chilenas são vistas como uma espécie de vitrine da América Latina, funcionando também como um laboratório do neoliberalismo.

No entanto, esses dados "positivos", apesar de ostentarem bons indicadores econômicos, também camuflam uma grande desigualdade. De acordo com a Ministra do Desenvolvimento Social à época da pesquisa, María Fernanda Villegas, 14,4\% dos chilenos viviam em situação de pobreza e 4,5\%, na extrema pobreza (EXAME, 2015). A economia do Chile tem como base principal o setor de serviços, que representava, em 2010, 66,5\% do PIB. O setor da mineração vem em segundo lugar, com 19,2\% do PIB. Já quanto à balança comercial, as exportações representam 34,2\% do PIB, e as importações, 28,3\% (OCDE, 2012).

Outro dado importante, destacado pela Organização das Nações Unidas (ONU), é quanto ao Índice de Desenvolvimento Humano (IDH) do Chile, que é o maior da América Latina, tendo ficado em $40^{\circ}$ lugar no ranking mundial (2013).

Quanto ao produto interno bruto chileno (PIB), no ano de 1990, era de 31,5 bilhões de dólares; no ano de 2000 foi de 79,32 bilhões, e no ano de 2014, 258,1 bilhões de dólares (BANCO MUNDIAL, 2015). Quanto ao PIB per capita, no início dos anos 1990, era de 2.401 dólares, e em 2014 foi de 14.528 dólares (BANCO MUNDIAL, 2015). 
O sistema educacional do Chile é descentralizado, pois cada estabelecimento é administrado por gestores, instituições municipais ou particulares, denominados de sostenedores, que se responsabilizam pela entidade educacional diante do Estado. Segundo o Ministério da Educação do Chile, as instituições de ensino podem ser municipais, estatais, particulares subvencionadas e particulares. Salazar (2014) afirma que, de acordo com a OCDE, apenas 32\% das instituições de ensino são públicas; as demais, subvencionas ou privadas.

Quanto aos níveis de ensino, o sistema chileno de educação compõe-se de: a) educação infantil, chamada de "parvularia", para crianças entre 84 dias de vida até 5 anos; b) educação geral básica, para crianças entre 5 e 13 anos de idade, dividida em oito séries; c) ensino médio, para estudantes de 13 a 18 anos de idade, divididos em quatro séries; d) ensino médio técnico profissional; f) ensino superior. Quanto às modalidades de ensino, referem-se a: a) educação de jovens e adultos; b) educação intercultural; c) educação especial (MINEDUC, 2015).

Quanto ao financiamento da educação, o Chile foi o primeiro país da América Latina a cobrar mensalidades em instituições públicas de ensino superior, já na década de 1980 (OCDE, 2009). Quanto aos gastos com educação superior no Chile, segundo a OCDE, em 2010 o total foi de 2,5 do PIB, muito superior à média dos outros países membros da OCDE, que é de $1,6 \%$ do PIB. No entanto, dois terços desses fundos provêm de fontes privadas $(1,6 \%$ do PIB), e somente um terço, cerca de $0,8 \%$ do PIB, é oriundo dos fundos públicos. Desta forma, o Chile tem um dos gastos públicos diretos mais baixos dos países membros da ODCE, em relação ao ensino superior. (OCDE, 2011). Quanto ao gasto por estudante do ensino superior, ainda segundo a OCDE (2011), no ano de 2010 o Chile gastou USD 6.863, enquanto que a média da OCDE era de USD 13.728.

Já a Educação Especial no Chile, de acordo com a Lei Geral de Educação, Ofício no . 7990 (CHILE, 2009), é uma modalidade do sistema educacional e deve desenvolver suas ações de forma transversal, em todos os níveis de ensino, para estudantes com deficiência, tanto nas instituições de ensino regular como naquelas de ensino especial. A Educação Especial, segundo a Lei $\mathrm{n}^{\circ} .20 .422$ (CHILE, 2010), tem o objetivo de prover um conjunto de serviços, recursos humanos e técnicos especializados, para, assim, atender crianças, jovens e adultos com deficiência, de tal maneira que se desenvolvam e avancem no currículo nacional, em igualdade de condições e oportunidades. De acordo com MINEDUC (2015), na 
atualidade, aproximadamente 300.000 pessoas têm algum tipo de necessidade educacional especial $^{3}$.

Apesar dos avanços constatados no sistema de educação chilena, decorrentes de maior democratização e acesso ao ensino em todos os níveis e modalidades, ainda há muitos desafios a serem enfrentados, como melhorar a qualidade do ensino e enfrentar a questão das desigualdades socioeconômicas, que acabam por se refletir nas instituições de ensino.

\section{Contexto Educacional do Brasil}

O Brasil é uma República Federativa, com uma população de 201,5 milhões de pessoas, de acordo com a Pesquisa Nacional por Amostra de Domicílios (PNAD) de 2013 (IBGE, 2013).

Quanto à economia, houve um crescimento no Produto Interno Bruto (PIB) na última década (2006-2016) e uma redução na desigualdade de renda. Ao cruzar estas informações, percebe-se que a vida da população melhorou. Isto pode ser atribuído a diferentes fatores, de acordo com o IBGE (2014): conjuntura internacional favorável a exportações, políticas de valorização do salário mínimo, programas de transferência de renda, evolução nos rendimentos do trabalho, entre outros.

No início dos anos de 1990, o PIB brasileiro era de 461,951 bilhões de dólares. Já nos anos de 2000, chegou à soma de 657,216 bilhões de dólares e no ano de 2014, o PIB foi de 2.417 trilhões de dólares (BANCO MUNDIAL, 2016). No entanto, os índices econômicos começaram a mostrar uma retração de 10,2\%, entre 2011 e 2014, ficando o PIB em 2.346 trilhões de dólares, com uma queda de 10,2\%, em três anos, e chegando, em 2016, ao valor de 1.794 trilhões.

Quanto ao PIB per capita, também se observa um aumento significativo. Em 1990 era de 3.071 dólares, e em 2014, de 11.384 dólares por ano. Em relação ao PIB per capita, em 2011, o valor foi de 12.310 dólares, e em 2014 foi de 11.530 dólares, significando uma queda de 6,3\% nesse mesmo período. Em 2016, o valor chegou a 8.850 dólares (BANCO MUNDIAL, 2016)

Também de acordo com o relatório do Programa das Nações Unidas para o Desenvolvimento (PNUD), nas últimas décadas houve melhora no Índice de Desenvolvimento Humano (IDH) do Brasil. Este, que avalia as três variáveis, renda, saúde e educação, aponta que houve, neste sentido, um crescimento de 47,5\% entre 1991 e 2010.

\footnotetext{
${ }^{3}$ A nomenclatura utilizada pelo Mineduc, à época, era Pessoa com Necessidades Educacionais Especiais.
} 
(ACAYABA; OLIVEIRA, 2013). Em 2014, o Brasil ficou com um IDH de 0,744 e o país aparecia na $79^{\mathrm{a}}$ posição entre os 187 países e territórios reconhecidos pela Organização das Nações Unidas (ONU). Até 2016, não houve avanço nesta posição.

Em relação à organização do sistema educacional do país, esta é coordenada pela União, os Estados, o Distrito Federal e os Municípios em regime de colaboração. Cada ente federado tem suas responsabilidades formalizadas na Lei de Diretrizes e Bases da Educação (LDB, 1996). É um sistema descentralizado, levando em conta a organização, a gestão e o financiamento. No caso da Educação Superior, é a Secretaria de Educação Superior (Sesu) do Ministério da Educação (MEC) que coordena, planeja e supervisiona a formulação e a implementação da Política Nacional de Educação Superior. Além disso, é da sua responsabilidade desenvolver, manter e supervisionar as instituições públicas de ensino superior e, também, as instituições de ensino superior privadas, segundo a LDB (BRASIL,1996).

Quanto aos níveis de ensino e modalidades de educação, o sistema brasileiro de educação compõe-se, segundo o Art. 21 da LDB (BRASIL, 1996), de: I - educação básica, formada pela educação infantil, ensino fundamental e ensino médio; II - educação superior. E as modalidades contempladas, no Art. 78 da mesma lei, são: educação especial, educação de jovens e adultos, educação profissional e tecnológica, e educação escolar bilíngue e intercultural, em atenção aos povos indígenas (BRASIL, 1996).

Quanto ao ensino superior, de acordo com os dados dos censos de 2003 e de 2013 do Ministério da Educação e do Instituto Nacional de Estudos e Pesquisas Educacionais Anísio Teixeira (MEC/INEP), houve um aumento, na década, de $187,95 \%$ no número total de estudantes matriculados, que passou de 3.887.022 para 7.305.977. (BRASIL, 2013), considerando matrículas presenciais e a distância.

Quanto ao financiamento educacional, observa-se um aumento no investimento público direto cumulativo por estudante entre 2000 e 2013, levando em conta a duração de cada nível de ensino. Por exemplo, na educação básica, em 2000 foram gastos $\mathrm{R} \$ 26.577,00$ por aluno e, em 2013, o valor chegou a R \$76.940,00. Já no ensino superior, o gasto por estudante, no ano 2000, foi de $\mathrm{R} \$ 80.225,00$ e, em 2013 , de $\mathrm{R} \$ 85.531,00$. O nível com maior investimento é o ensino superior, e ao longo do período houve um aumento no gasto. Destacase o incremento do orçamento das universidades federais, “[...] em 2013, foram investidos R\$ 440 milhões na expansão e consolidação das instituições, $\mathrm{R}$ \$ 509 milhões na implantação de novos campus e R 300 milhões na implantação de novas universidades, totalizando $\mathrm{R}$ \$1,2 bilhão.” (MEC, 2014, p. 29). 
Os dados apresentados mostram as contradições do contexto e seus reflexos no sistema educacional. Existe um aparato legal que prevê educação de qualidade para todos, tanto no Chile como no Brasil, mas na prática o que predomina é a subserviência ao mercado econômico e ao modelo neoliberal.

Assim, nos parece que é nesta "arena" do campo político que avanços e retrocessos acontecem no processo de construção de um sistema educacional que almeje ser universal e de qualidade.

\section{As universidades pesquisadas, os estudantes com deficiência e as políticas e ações institucionais para o acesso ao ensino superior}

As universidades pesquisadas foram: Universidade de Talca (UTALCA), no Chile, e a Universidade Federal do Paraná (UFPR). E, de forma presencial, foram entrevistados 33 estudantes com deficiência, e quatro gestores das duas universidades ${ }^{4}$.

Para melhor contextualizar a pesquisa, inicialmente fazemos aqui uma exposição, caracterizando as universidades e os sujeitos de pesquisa, para, em seguida, apontar os dados encontrados.

A Universidade de Talca (UTALCA) é uma das 25 universidades que integram o Conselho de Reitores das Universidades Chilenas (CRUCH). Foi fundada em 1981, a partir de uma fusão entre a Universidade do Chile e a Universidade Técnica do Estado. A reitoria fica na cidade de Talca, na região de Maule. Em 2014, a universidade tinha cerca de 10.300 estudantes matriculados em cursos de graduação e 1.160 na pós-graduação strictu sensu e especializações (UTALCA; DEMRE, 2015). A universidade oferece ensino público (com pagamento de mensalidades), sem fins lucrativos.

Essa Universidade também dispõe de um centro de apoio aos estudantes, a Vicereitoria de Desenvolvimento Estudantil, que busca implementar programas e serviços de apoio aos alunos. Possui uma equipe de profissionais que prestam apoio socioeconômico, serviços de saúde física e psicológica, programas culturais e esportivos.

Apesar da boa infraestrutura do espaço físico, a universidade não tinha nenhum centro ou núcleo de apoio para os estudantes com algum tipo de deficiência. Em entrevista realizada com o diretor de planejamento e análise institucional da Utalca (2014), ele afirmou que naquele momento estava coordenando o projeto de inclusão na Universidade Utalca

\footnotetext{
${ }^{4}$ A pesquisa contou com o apoio da CAPES, por meio de uma bolsa sanduíche junto ao Programa Institucional de Bolsas de Doutorado Sanduíche no Exterior (PDSE), no ano de 2014.
} 
denominado "Compromisso da Universidade de Talca com a plena integração, de pessoas com capacidades diferentes, às práticas corporativas".

Até o momento da pesquisa, a universidade não tinha nenhuma política efetiva para o acesso e a permanência de candidatos ou estudantes com algum tipo de deficiência. O projeto citado tinha a duração de apenas um ano, e não encontramos, no Plano Estratégico Institucional 2015, nenhuma menção a esse alunado.

Quanto ao perfil dos estudantes com deficiência da Universidade de Talca, não havia, na instituição, nenhum registro acerca dos estudantes com deficiência. Para realizar o mapeamento, foi necessário visitar cada faculdade. Com as informações obtidas (principalmente, via e-mails institucionais) foi possível o primeiro contato com cada um dos 11 sujeitos identificados. Neste momento, eram agendados o dia e o horário mais convenientes para o participante. As entrevistas foram realizadas no Instituto de Investigação e Desenvolvimento Educacional (IIDE).

Dos seis estudantes que deram a entrevista, dois eram do sexo feminino $(33,3 \%)$, e quatro do sexo masculino (66,7\%). A idade média dos participantes era de 22,7 anos. Constatou-se que cinco sujeitos têm deficiência física $(83,3 \%)$ e uma estudante tem uma doença crônica $(16,7 \%)$. Três participantes referiram que a causa da sua deficiência foi anoxia neonatal; um, acidente de carro, outro, má formação. Verificou-se que cinco estudantes recebem bolsas ou fazem empréstimo para pagar a universidade, e também recebem auxílio da família para manutenção das despesas.

Nas Universidades do Chile, como já destacado, mesmo nas públicas os estudantes pagam mensalidades. Esta questão, a do financiamento e pagamento de mensalidades no ensino público, é alvo de muitas críticas no país. A maioria dos estudantes que participou das entrevistas manifestou descontentamento e revelou que suas famílias sofrem para pagar os custos das mensalidades, manutenção, alimentação e materiais. Para minimizar o endividamento das famílias, o Ministério da Educação criou um complexo sistema de bolsas de estudo e créditos que, na forma de empréstimos, são oferecidos aos estudantes.

Quanto à trajetória dos estudantes no ensino regular ou especial, todos afirmaram ter estudado no regular. Com relação a terem estudado em escolas privadas, municipais (públicas e gratuitas) ou subvencionadas (privadas com subsídios do governo), observou-se que dois sujeitos estudaram somente no ensino privado, dois estudaram em instituições públicas e um fez parte dos estudos no ensino privado (básica até o $5^{\circ}$ ano) e parte na escola pública, e um participante estudou somente no ensino subvencionado. 
Outro dado, considerado relevante para esta pesquisa, diz respeito aos serviços e atendimentos educacionais de apoio à escolarização desse alunado, no decorrer da educação básica até o ensino superior, e se os atendimentos eram públicos ou privados. Dos participantes da pesquisa, três tiveram atendimento especializado na Fundação Teletón. No Chile, esta instituição arrecada milhões de pesos chilenos por ano, por meio de um programa televisivo. Desta forma, percebe-se a "isenção" do Estado quanto à responsabilização financeira das políticas relacionadas ao atendimento de estudantes com deficiência na educação superior.

Quanto à seleção para o ensino superior no Chile, uma das formas mais usuais é a Prova de Seleção Universitária (PSU). A primeira aplicação foi em 2003 e, ao longo dos últimos anos, o sistema vem se consolidando. A PSU é realizada em todo território nacional para estudantes que tenham terminado ou estejam finalizando o Ensino Médio. A responsabilidade sobre o processo é do Conselho de Reitores das Universidades Chilenas $(\mathrm{CRUCH})$, que reúne as universidades denominadas públicas, credenciadas e outras universidades privadas inscritas. Atualmente, 25 universidades chilenas fazem parte deste Conselho e utilizam a PSU como forma de avaliação para o ingresso em suas instituições.

De acordo com o Diretor do DEMRE (2014), cerca de 270 mil candidatos participaram do processo seletivo de 2013/2014, sendo que, desses, 40 a 50 estudantes declararam ter algum tipo de deficiência.

No caso dos participantes da nossa investigação, todos os seis sujeitos prestaram a PSU e fizeram cursos preparatórios privados.

Sendo a Universidade de Talca parte do $\mathrm{CRUCH}$, é orientada por políticas institucionais formuladas e implementadas por este conselho. No documento oficial de Normas e Aspectos Importantes para o Processo de Admissão do CRUCH de 2015, já estavam elencadas as distintas etapas do processo para o ano de 2016: a inscrição, os termos e as condições para participação do processo, as provas, o sistema de pontuação, a seleção e a postulação da vaga nas universidades pretendidas.

No que diz respeito a candidatos que tenham alguma deficiência, o documento afirma na parte VI: “[...] se entende como "discapacitada" toda pessoa que, como consequência de uma ou mais deficiências físicas sensoriais (congênitas ou adquiridas), não possa submeter-se à bateria de provas PSU® em seu formato padrão com o uso de lápis e papel". (CRUCH, 2015, p. 30, tradução nossa).

Para estes candidatos denominados "discapacitados", o documento prevê um atendimento especial. A maior ênfase é nos casos de pessoas com deficiência física e motora, 
não constando no documento o acesso de pessoas com surdez, cegueira, baixa visão ou com deficiência intelectual. No caso de pessoas com doenças mentais, gagueira e outros distúrbios de linguagem, não haverá uma atenção especial, visto que estes grupos não apresentam impedimentos para fazer as provas escritas.

Nesse documento também estão registrados os procedimentos a serem seguidos pelos candidatos com alguma discapacidad: os estudantes interessados devem apresentar seu pedido por escrito para o DEMRE, dentro do prazo estabelecido.

No caso dos candidatos cegos, em função da dificuldade de acessar os elementos visuais que aparecem nas provas, seu ingresso à educação universitária se dá por meio de Admissão Especial nas diversas universidades que integram o sistema e em cursos compatíveis com sua condição. Mas, se apesar de sua condição, o candidato cego desejar submeter-se à prova normal de lápis e papel, o DEMRE proporcionará a assistência de dois ledores para auxiliar com a leitura e o preenchimento da folha de respostas (CRUCH, 2015, p. 31, tradução nossa).

Está claro no documento oficial que trata das normas para a PSU que, apesar de contemplar aspectos importantes para o acesso do estudante com deficiência, o processo não garante opções de acessibilidade para pessoas cegas (provas ampliadas, em Braile ou no computador). Também não existe menção a pessoas surdas. Além desta questão de acessibilidade, destacamos o fato de que mesmo que a pessoa com deficiência faça a prova e atinja a pontuação necessária, isso não garante seu acesso, visto que são as universidades que irão determinar se o estudante pode ou não fazer o curso, levando em conta se os cursos estão preparados ou não para recebê-lo.

O fato de a universidade decidir se receberá o estudante ou não, de acordo com suas condições de acessibilidade, em nossa percepção fere o direito do aluno que obteve a pontuação necessária para fazer o curso que deseja. Ouvimos dos estudantes relatos acerca de candidatos que não puderam fazer o curso escolhido por serem cegos ou surdos. E a justificativa era a de que "os cursos não estavam preparados, que não tinham material adaptado e os docentes não estavam preparados para esta demanda". Neste sentido, a universidade não assume seu papel e sua missão como formadora e legitimadora dos direitos dos estudantes com deficiência. No caso da UTALCA, atualmente, só estão matriculados estudantes com deficiência física e motora.

No caso dos participantes da pesquisa, quatro deles sinalizaram no formulário de inscrição da PSU que tinham uma “discapacidad”, mas nem todos tiveram as condições adequadas na hora da prova. Isso reforça a importância do candidato se identificar e preencher 
corretamente os documentos na inscrição. Já no caso institucional, o desafio é elaborar documentos oficiais com acessibilidade, que não deixem dúvidas, e oferecer um atendimento que garanta os direitos de acesso dos candidatos. Para ambos os lados há desafios a serem vencidos em cada etapa do processo, uma vez que o candidato realiza a PSU, postulará, com o escore obtido a partir da pontuação alcançada na prova, uma vaga nos cursos oferecidos pelas instituições de ensino superior.

Como se pôde constatar, a UTALCA estava no início do processo de construção de políticas para o acesso dos estudantes com deficiência. Existe uma contradição entre as proposições de ser uma universidade inovadora e de excelência e as ações institucionais que decidem se um estudante pode ou não fazer um curso, de acordo com as condições de adaptação e acessibilidade da instituição, não sendo levado em conta o direito da pessoa com deficiência.

Quanto à Universidade Federal do Paraná, esta foi fundada em 1912, na cidade de Curitiba. Essa instituição centenária possui, atualmente, 117 cursos de graduação, 69 de mestrado acadêmico, 49 de doutorado e 5 de mestrado profissional, e sua comunidade acadêmica conta com mais de 40 mil pessoas. (UFPR, NC/UFPR, 2014, 2015).

O ingresso aos cursos de graduação da UFPR acontece por meio de exame vestibular, que é realizado anualmente para selecionar os candidatos. Todo processo é coordenado pelo Núcleo de Concursos da Pró-reitoria de Graduação da instituição.

Desde 1991, a UFPR, por meio da Resolução do CEPE/UFPR nº. 27/91, tem bancas especiais para candidatos com deficiência. Segundo Moreira, Bolsanello e Seger (2011), esta pode ser considerada a primeira iniciativa da universidade, no sentido de garantir, a estes participantes, acessibilidade ao processo seletivo da instituição. Em 2006, foi fundado o Núcleo de Apoio às Necessidades Educacionais, o NAPNE. Naquele momento, o núcleo foi um importante espaço político, para reflexão, discussão, formulação e colocação em prática de políticas institucionais que atendessem toda a comunidade acadêmica: estudantes, funcionários, professores e a sociedade de forma geral.

A partir de 2007, o NAPNE começou a participar na organização das bancas especiais junto ao Núcleo de Concursos (NC), visando atender, no exame vestibular da instituição, os candidatos com algum tipo de NEE. Em 2008 foi aprovada pelo Conselho Universitário a Resolução n. 70/08-COUN, que afirma em seu Art. $2^{\circ}$ : Aprovar a destinação de 01 (uma) vaga em cada curso de graduação, de ensino profissionalizante e de ensino médio da UFPR, para pessoas com deficiências, a partir do Processo Seletivo 2008/2009 (UFPR, 2008). A partir de 2008/2009, pessoas com deficiência passaram a concorrer a uma vaga suplementar 
por curso, de acordo com o Edital do Processo Seletivo de cada ano, sempre na segunda fase do exame vestibular.

A partir dos dados dos estudantes com deficiência, fornecidos pelo NAPNE, foi possível entrar em contato com 33 sujeitos. Foram realizadas, no entanto, apenas 27 entrevistas, no próprio NAPNE ou nas dependências da Biblioteca da UFPR (Reitoria ou Politécnico), em salas privadas que garantiram um ambiente silencioso e com sigilo.

Quanto à caracterização dos estudantes, 15 eram do sexo masculino (55,56\%), e 12 do sexo feminino (44,44\%). Quanto à idade, a média foi de 23/25 anos. Em relação às deficiências, havia três participantes com cegueira total $(11,11 \%)$ e dois com baixa visão $(7,41 \%)$, seis participantes surdos $(22,22 \%)$, sendo que cinco eram oralizados e um bilíngue (fluente na Língua Brasileira de Sinais e oralizado). No caso da deficiência física, o total de sujeitos foi de $16(59,26 \%)$, sendo cinco estudantes com paralisia cerebral, causada por falta de oxigenação à hora do nascimento $(18,52 \%)$, três por acidentes automobilísticos $(11,11 \%)$, dois por arma de fogo $(7,41 \%)$, um por acidente. Os outros cinco por problemas congênitos, má formação ou causa não identificada.

Os estudantes com deficiência estão matriculados em diferentes cursos das várias áreas do conhecimento: Ciências Exatas e da Terra, Ciências Biológicas, Engenharias, Ciências da Saúde, Ciências Agrárias, Ciências Sociais Aplicadas, Educação e Artes (CNPQ, 2013). Esta distribuição evidencia um interesse diversificado dos estudantes e sua participação em diferentes campi da universidade. Outro dado importante é que dos 27 participantes, sete fazem cursos no turno da noite, e 20 no período diurno.

Constatamos que dos 27 estudantes, 24 (88,89\%) só estudaram em instituições de ensino regular. Importante frisar que cinco deles não apresentaram deficiência durante a infância e a adolescência. Dois sujeitos, Rafael e Laurence, com deficiência visual, frequentaram ensino especial durante a educação infantil, para aprender Braile, e Carmem, com surdez, frequentava, em um turno, o ensino regular, e no outro, o ensino especial, durante a educação infantil e fundamental. Esses dados confirmam a implementação, no Brasil, das políticas educacionais inclusivas já na década de 1990.

Dos 27 sujeitos, 11 estudaram somente no ensino público em todos os níveis, dez, em escolas privadas, dois receberam bolsas para estudar no ensino privado, e os outros quatro estudaram em escolas privadas e públicas ao longo da sua escolaridade.

Dos 27 estudantes, 12 tiveram atendimento no sistema público, dez só tiveram atendimentos no sistema privado (planos de saúde ou consultas particulares), um estudante, durante toda infância, adolescência e parte da vida adulta, teve atendimentos públicos e, 
atualmente, recebe atendimento fisioterápico particular. Dois participantes foram atendidos pela Associação de Pais e Amigos do Excepcional (APAE), e um, pela Rede Sarah de Hospitais de Reabilitação.

Os atendimentos educacionais especializados e outros serviços devem fazer parte das políticas educacionais em todos os níveis e modalidades, bem como a garantia do seu financiamento. Sem isso, corremos o risco de não oferecer uma educação de qualidade às pessoas com deficiência e perpetuar as condições de desigualdade ao acesso escolar.

No Brasil, existem formas diferenciadas para ingressar na Universidade. Entre as mais comuns, estão o Processo Seletivo para o Ingresso nas Universidades (exame vestibular) e o Exame Nacional do Ensino Médio (ENEM).

No caso da UFPR, o Processo Seletivo consiste de provas que avaliam o domínio dos conteúdos do Ensino Médio e a capacidade de articular ideias e de raciocinar de maneira lógica. A UFPR, em edital próprio para o processo seletivo de 2015/2016, destinou 30\% das vagas para candidatos que utilizarem a nota do ENEM, por meio do Sisu (NC/UFPR, 2015).

O Exame Nacional do Ensino Médio (ENEM) é organizado e gerenciado pelo Instituto Nacional de Estudos e Pesquisas Educacionais Anísio Teixeira (INEP). Trata-se de uma prova nacional, realizada em todos os estados da Federação e no Distrito Federal.

É fundamental, portanto, que o candidato declare, em sua inscrição, que tem uma deficiência ou uma necessidade educacional especial, possibilitando que a comissão organizadora providencie os recursos materiais, técnicos e humanos adequados para seu atendimento.

Destacamos também que o Edital nº. 28/2015 tem uma versão na Língua Brasileira de Sinais, gravada por dois intérpretes, e solicita que os candidatos entreguem os seguintes documentos comprobatórios: atestado médico, formulário de solicitação para atendimento especial, parecer técnico-pedagógico, exame de audiometria para candidatos com surdez/deficiência auditiva, exame oftalmológico e atestado de funcionalidade. Depois da entrega, os candidatos são convocados para uma Banca de Verificação. Esta banca tem por incumbência entrevistar o candidato, validar os documentos apresentados e verificar se o mesmo atende a todos os itens do edital. O resultado é divulgado no site do NC/UFPR por meio de uma lista onde constam os nomes dos candidatos que irão concorrer à vaga para pessoa com deficiência. (UFPR/NC, 2015).

Quanto ao dia da prova, grande parte dos estudantes relata que foi bem atendido, em um local apropriado e com uma equipe preparada (professores especializados, intérpretes de Libras e ledores). 
Os gestores institucionais entrevistados conhecem as demandas dos estudantes e apontam que é um desafio atender a todas as especificidades dos candidatos. Nem sempre a Universidade tem, em seu quadro, profissionais especializados nas áreas requeridas. Então o NAPNE, em conjunto com o Núcleo de Concursos, contrata estes profissionais para o dia da prova, bem como organiza toda logística e acessibilidade para que os candidatos tenham suas necessidades especiais atendidas.

Percebeu-se que entre o processo seletivo da UFPR e o ENEM há semelhanças (atendimento especializado para pessoas com deficiência e outras necessidades educacionais especiais) e diferenças. O ENEM prevê uma hora a mais para os participantes com deficiência. Também não existe uma banca de verificação dos documentos comprobatórios. Já a UFPR, além da solicitação de documentos comprobatórios, realiza uma banca de verificação e procura acompanhar o estudante em todo processo, desde a inscrição até a sua permanência na universidade.

Depois que o estudante é aprovado no exame do vestibular, o NAPNE faz o acompanhamento da sua matrícula e da sua permanência na universidade.

Ao receber o nome dos estudantes com deficiência aprovados e seus respectivos cursos, o núcleo envia uma carta, por e-mail ou malote, e informa por telefone para o coordenador do curso, informando a respeito do estudante e das especificidades quanto a sua acessibilidade.

Apesar de todas as ações do NAPNE nessa primeira etapa, inscrição, banca de verificação, banca especial no dia da prova, acompanhamento da matrícula e contato com os coordenadores dos cursos, constata-se que alguns candidatos não se identificam como pessoas com deficiência e só depois do ingresso é que são localizadas pelo NAPNE. Isso dificulta o processo de acompanhamento e, às vezes, a própria permanência do estudante na universidade.

Para que as ações institucionais do NAPNE sejam possíveis, além dos recursos humanos, técnicos e financeiros disponibilizados pela própria universidade, o núcleo recebe recursos do Programa de Acessibilidade na Educação Superior (Incluir), do Governo Federal, desde 2006 (BRASIL, 2013). A UFPR tem participado de todas as chamadas do edital, recebendo recursos que auxiliaram/auxiliam na compra de equipamentos e outras demandas do núcleo.

Foi possível perceber que as ações institucionais existem e que estão em constante processo de avaliação, formulação e aprimoramento. Estudantes com deficiência almejam ingressar no ensino superior e têm muito a contribuir para o avanço das políticas 
institucionais. Neste sentido, a universidade deve fomentar a participação efetiva desse alunado. Na entrevista realizada com os gestores, a assistente administrativa do NAPNE disse que existe uma proposta para se criar um grupo de convivência, onde os próprios estudantes participem.

Essa iniciativa vem ao encontro da Lei $\mathrm{n}^{\mathrm{o}}$. 13.146 que, em seu artigo 28, inciso VII, prevê a "participação dos estudantes com deficiência e de suas famílias nas diversas instâncias de atuação da comunidade escolar." (BRASIL, 2015, p. 1).

\section{Considerações finais}

Este estudo mostrou que nos dois países pesquisados já existe um aparato legal que garante os direitos educacionais das pessoas com deficiência, em todos os níveis e modalidades. O mesmo, no entanto, não é cumprido efetivamente, considerando que no caso do ensino superior a exclusão social é maior, se comparada com os demais níveis de ensino, para todos os estudantes, tenham ou não uma deficiência.

Constatou-se, também, que tanto a educação superior chilena quanto a brasileira refletem, cada uma a sua maneira, fatores históricos, sociais, econômicos e culturais similares, mas também díspares.

No caso de pessoas com deficiência, lhes foi negado historicamente o acesso ao ensino superior, considerando que este grupo não era visto como uma elite intelectual ou financeira e nem como qualificada para o trabalho. Pessoas cegas, surdas, com deficiência motora ou intelectual, entre outras, sofreram o isolamento social, ficando à mercê do atendimento assistencialista e filantrópico, com poucas perspectivas de fazer um curso superior.

Ao se fazer a análise dos documentos legais a partir da década de 1990, com a formulação e a colocação em prática de políticas educacionais de inclusão escolar por meio de instrumentos legais, verificou-se um aumento no ingresso desses estudantes no ensino superior, tanto no Chile quanto no Brasil, numa contraposição à exclusão histórica das décadas anteriores. No entanto, estes números ainda não são significativos, pois só 6,6\% das pessoas com deficiência no Chile têm curso superior (FONADIS, 2006), e no Brasil, 6,7\% (IBGE, 2010), num quadro em que, no caso de estudantes sem deficiência, os percentuais são de $21 \%$ da população brasileira (IBGE, 2013) e, no caso do Chile, 21,8\% (OCDE, 2015).

A pesquisa mostra que romper com a lógica mercantilista na educação não é tarefa fácil, exige vigilância constante e comprometimento com uma universidade pública, 
autônoma e gratuita. O que ficou evidente nesta investigação é que, muitas vezes, acontece um "transformismo", ou um gatopardismo, como é denominado no Chile, ou seja, muda-se para se permanecer da mesma forma, perpetuando as formas antigas e conservadoras, baseadas em um modelo econômico e social que privilegia o capital, em detrimento de uma educação como direito de todos.

No caso do Chile, as universidades públicas mantêm um complexo sistema de financiamento, e mesmo com a nova Lei $\mathrm{n}^{\circ} .20 .890$, de 28 de dezembro de 2015, apenas uma parcela dos estudantes tem sido beneficiada. A gratuidade não é para todos, diferente do que acontece no Brasil, que prevê que a universidade pública seja também gratuita.

Neste sentido, pode-se afirmar que o direito à educação de pessoas com deficiência é violado constantemente, apesar de toda legislação em vigor, tanto no Chile como no Brasil. Os motivos, de acordo com a investigação, estão enraizados em um Estado neoliberal que age de acordo com as leis do mercado. O direito à Educação para pessoas com deficiência não é natural e não foi dado sem uma construção coletiva e histórica. Trabalham, nesta causa, os próprios sujeitos, seus familiares, educadores, pesquisadores, partidos e o Estado, em todas as suas esferas: legislativa, executiva e judiciária.

Em relação às instituições pesquisadas, comprovou-se que no caso da Utalca, no Chile, ainda não há uma política institucional para o atendimento dos estudantes com deficiência e a quantidade de bolsas de estudo direcionadas para este público é pequena. Em 2015, a soma de bolsas denominadas de "beca discapacidad" para todo país contemplava 450 indivíduos. Já na UFPR houve um avanço nas políticas institucionais e governamentais, que possibilitaram um maior acesso desse alunado.

Mesmo com as diferenças entre as universidades, constatou-se que existem lacunas entre o que se vive no contexto acadêmico e o que dizem os dispositivos legais. Os estudantes relataram ter encontrado dificuldades de acesso ao ensino superior, por razões financeiras. No caso da UFPR, os custos de manutenção e a falta de programas de assistência direcionados para este alunado, e no caso da UTALCA, o pagamento de mensalidades ou o endividamento das famílias. Também relataram questões sobre suas especificidades na trajetória escolar, evidenciadas pelo custo dos tratamentos e cirurgias, em alguns casos, falta de profissionais de apoio, em outros. Além disso, narraram ter encontrado barreiras arquitetônicas, comunicacionais (falta de informações acessíveis nos editais e de intérpretes da língua de sinais) e atitudinais durante o processo de ingresso às instituições pesquisadas. 
A partir do estudo realizado e dos relatos dos estudantes chilenos e brasileiros, elencamos alternativas e proposições, algumas sugeridas pelos próprios participantes e gestores. Estas visam à manutenção e ao avanço das políticas e ações governamentais e institucionais que dizem respeito ao acesso dos estudantes com deficiência no ensino superior, tanto no Chile como no Brasil. Subdividimos de acordo com as quatro categorias analisadas ao longo da tese: 1) Contexto educacional; 2) Educação superior 3) Políticas de financiamento e 4) Políticas de acesso ao ensino superior para estudantes com deficiência no Chile e no Brasil.

1) Contexto educacional:

a) defesa da universidade pública, gratuita e inclusiva, considerando este aspecto fundamental para autonomia e construção de políticas institucionais;

2) Educação superior:

a) participação mais efetiva dos estudantes, professores e pesquisadores com deficiência na construção de políticas governamentais e institucionais de acesso ao ensino superior;

b) apresentação da temática a respeito do acesso e permanência dos estudantes com deficiência nos cursos de graduação e pós-graduação, estabelecendo linhas de pesquisa para investigar as políticas governamentais e institucionais voltadas para este alunado;

c) ampliação do debate com a comunidade acadêmica sobre o acesso desse alunado às instituições de ensino superior;

d) d)criação de convênios institucionais de cooperação e investigação científica sobre a temática entre os países da América Latina;

e) criação de mecanismos de avaliação e acompanhamento das políticas institucionais, no que diz respeito ao acesso desse alunado;

3) Políticas de financiamento:

a) criação de vagas para professores e profissionais especializados, nas universidades, que possam atuar tanto no acesso como na permanência desse alunado;

b) manutenção e ampliação de recursos destinados à implementação de políticas de acesso ao ensino superior para estudantes com deficiência;

c) aplicação de recursos que garantam acessibilidade arquitetônica, tecnologia, equipamentos, elaboração de material didático, entre outros;

4) Políticas de acesso ao ensino superior para estudantes com deficiência no Chile (UTALCA) e no Brasil (UFPR):

a) ampliação do debate, com a comunidade acadêmica, sobre o acesso desse alunado às instituições de ensino superior; 
b) consideração das especificidades educacionais das pessoas com deficiência no momento da elaboração dos editais e das provas de seleção e no atendimento nos dias de prova;

c) criação de fóruns e seminários interinstitucionais para troca de experiências entre IES brasileiras e internacionais;

d) organização de grupos de estudo com estudantes, professores e a comunidade acadêmica interessada na temática;

e) participação de estudantes com deficiência nas campanhas de divulgação dos processos de seleção das instituições de ensino superior;

f) ampliação de grupos e páginas nas redes sociais, com o objetivo de democratizar informações e promover o diálogo entre pares, estudantes e comunidade acadêmica.

Assim, para que um número maior de estudantes com deficiência tenha acesso ao ensino superior no Chile e no Brasil, é importante que o marco legal, estabelecido por meio de políticas governamentais e institucionais, seja consolidado, revisto, avaliado, questionado e aprimorado. Também, que estes sujeitos políticos sejam reconhecidos em suas especificidades e que seus direitos educacionais sejam legitimados, dentro e fora da universidade. Por fim, que haja um engajamento de todos, na luta por uma universidade pública, gratuita, autônoma e que, de fato, seja inclusiva.

\section{REFERÊNCIAS}

ACAYABA C.; OLIVEIRA M. IDH municipal do Brasil cresce 47,5\% em 20 anos, aponta PNUD, 2013. Disponível em: http://g1.globo.com/brasil/noticia/2013/07/idh-municipal-dobrasil-cresce-475-em-20-anos-aponta-pnud.html. Acesso em: 6 out. 2014.

BANCO MUNDIAL. Chile panorama general. Disponível em: http://www.bancomundial.org/es/country/chile/overview. Acesso em: 17 ago. 2015.

BARDIN, L. Análise de conteúdo. Lisboa: Edições 70, 1979.

BRASIL. Constituição da República Federativa do Brasil. Brasília, DF: Senado Federal, 1998.

BRASIL. Pesquisa Nacional de Amostra por domicílio. Síntese de Indicadores 2013. Disponível em: https://biblioteca.ibge.gov.br/visualizacao/livros/liv94414.pdf. Acesso em: 25 maio 2018.

BRASIL. Lei n. 9.394, de 20 de dezembro de 1996. Estabelece as Diretrizes e Bases da Educação. Diário Oficial da União, Brasília, DF, 23 dez. 1996. Disponível em:

http://www.planalto.gov.br/ccivil_03/leis/19394.htm. Acesso em: 20 jul. 2016.

BRASIL. Ministério da Educação. Programa de Acessibilidade à Educação Superior (Incluir). 2013. Disponível em:

http://portal.mec.gov.br/index.php?option=com_docman\&task=doc_download\&gid=12737\&Itemid =. Acesso em: 13 set. 2013 . 
CHILE. Chile en el panorama educacional internacional OCDE: avances y desafíos. Centro Estudios MINEDUC, ano. 2, n. 18, jun. 2013. Disponível em: https://centroestudios.mineduc.cl/wpcontent/uploads/sites/100/2017/06/A2N18_Chile_en_OECD.pdf. Acesso em: 5 jan. 2016.

CHILE. Constituición política de la República. Disponível em:

http://www.leychile.cl/Navegar?idNorma=242302. Acesso em: 22 out. 2013.

CHILE. Ley $\mathbf{N}^{\mathbf{0}} \mathbf{2 0 . 4 2 2}$ Establece normas sobre igualdad de oportunidades e inclusión social de personas con discapacidad. Disponível em: http://www.leychile.cl/Navegar?idLey=20422. Acesso em: 22 set. 2013.

CHILE. Ley General da Educación. Boletín No 4970-04. Disponível em:

http://especial.mineduc.cl/wp-

content/uploads/sites/31/2016/08/201304231523270.Ley_General_Educacion.pdf. Acesso em: 22

maio 2017.

CHILE. Mineduc entrega principales contenidos de la Reforma a la Educación Superior. 2015. Disponível em: http://www.redinformativa.cl/portada/2015/07/15/mineduc-entrega-principalescontenidos-de-la-reforma-a-la-educacion-superior/. Acesso em: 25 set. 2015.

CHILE. Instituciones vigentes. Sistema de Informação do Ensino Superior (SIES). Disponível em: http://www.mifuturo.cl/index.php/academicos-einvestigadores. Acesso em: 25 out. 2014.

DEMRE. Prueba de Selección Universitaria (PSU): etapas del proceso de admision. Disponível em: http://psu.demre.cl/proceso-admision/etapas-proceso-admision. Acesso em: 7 out. 2015.

DÍAZ, S. D. A reforma neoliberal da educação superior no Chile em 1981. Revista Brasileira de Ciências Sociais. v. 20, n. 57, p. 53-64, 2005. Disponível em:

http://www.scielo.br/scielo.php?pid=S0102-69092005000100004\&script=sci_abstract\&tlng=pt. Acesso em: 23 set. 2013. DOI: https://doi.org/10.1590/S0102-69092005000100004

EXAME. Desigualdade se mantém no Chile apesar de pobreza diminuir. Disponível em: http://exame.abril.com.br/mundo/noticias/desigualdade-se-mantemno-chile-apesar-de-pobrezadiminuir. Acesso em: 18 ago. 2015.

FERRER, F. Teoria y metodología de la educación comparada en la actualidad. Barcelona: Ariel, 2002. p. 91-152.

FONADIS. Fondo Nacional de Discapacidad. Disponível em: http://www.uchile.cl/portal/carpetade-prueba/79241/fondo-nacional-de-discapacidad-fonadis. Acesso em: 10 jan. 2016.

MOREIRA. L. C.; BOLSANELLO, M. A; SEGER, R. G. Ingresso e permanência da Universidade: alunos com deficiências em foco. Educar em Revista, n. 41, p.125-143, jul./set. 2011. Disponível em: http://www.scielo.br/scielo.php?pid=S0104-

40602011000300009\&script=sci_abstract\&tlng=pt. Acesso em: 18 ago. 2015. DOI:

https://doi.org/10.1590/S0104-40602011000300009

OCDE. Educational attainment, skills and participation in the labor market. 2015. Disponível em: http://www.keepeek.com/Digital-Asset-Management/oecd/education/education-at-a-glance- 
2015/chile_eag-2015-48-en\#page1. Acesso em: 15 jan. 2016. DOI: https://dx.doi.org/10.1787/eag2015-48-en

OCDE. Indicadores educacionais em foco. 2012. Disponível em: http://www.oecd.org/edu/skillsbeyond-school/INDICADORES\%20EDUCACIONAIS\%20EM\%20FOCO\%20N\%C2\%B07.pdf. Acesso em: 5 jan. 2015.

PNUD - Programa das Nações Unidas para o Desenvolvimento. Disponível em: http://www.pnud.org.br/HDR/Relatorios-Desenvolvimento-HumanoGlobais.aspx?indiceAccordion=2\&li=li_RDHGlobais. Acesso em: 26 maio 2015.

SALAZAR, P. Chile es el país con menor matrícula escolar pública en Latinoamérica. La Tercera, 20 set. 2014. Disponível em: http://www.latercera.com/noticia/nacional/2014/09/680-596593-9chile-es-el-pais-con-menor-matricula-escolar-publica-en-latinoamerica.shtml. Acesso em: $25 \mathrm{de}$ jan. 2016.

SENADIS. Censo 2012 en Discapacidad revela que las personas con discapacidad son el principal "grupo vulnerable" en Chile. 2013. Disponível em:

http://www.senadis.gob.cl/sala_prensa/d/noticias/2990/censo-2012-en-discapacidad-revela-que-laspersonas-con-discapacidad-son-el-principal-grupo-vulnerable-en-chile. Acesso em: 15 dez. 2015.

SOUZA, K. R.; SCAFF, E. A. da S.; KERBAUY, M. T. M. Políticas e gestão educacional na América Latina. Revista Ibero-Americana de Estudos em Educação, p. 1613-1620, ago. 2019. ISSN 1982-5587. Disponível em:

https://periodicos.fclar.unesp.br/iberoamericana/article/view/12751. Acesso em: 03 jan. 2020. doi: https://doi.org/10.21723/riaee.v14iesp.3.12751.

UNIVERSIDADE FEDERAL DO PARANÁ. Resolução n. 70/08 COUN. Conselho Universitário. Disponível em: www.ufpr.br/soc/descarregar_arquivo.php?cod=283. Acesso em: 5 jun. 2010.

UNIVERSIDADE FEDERAL DO PARANÁ. Secretaria dos Órgãos Colegiados. Resolução n. 27/91-CEPE. Curitiba, Paraná, 1991.

\section{Como referenciar este artigo}

ANSAY, Noemi Nascimento; MOREIRA, Laura Ceretta. Políticas de acesso ao ensino superior para estudantes com deficiência no Chile e no Brasil. Revista Ibero-Americana de Estudos em Educação, Araraquara, v. 15, n. 2, p. 539-559, abr./jun. 2020. E-ISSN: 19825587. DOI: https://doi.org/10.21723/riaee.v15i2.12475

Submetido em: 22/04/2019

Revisões requeridas: 30/07/2019

Aprovado em: 20/09/2019

Publicado em: 20/02/2020 